\title{
Chronic Daily Headache in Children and Adolescents: A Multi-Faceted Syndrome
}

\author{
Shashi S. Seshia, Shuu-Jiun Wang, Ishaq Abu-Arafeh, Andrew D. Hershey, \\ Vincenzo Guidetti, Paul Winner, Çiçek Wöber-Bingöl
}

\begin{abstract}
Chronic daily headache (CDH) is a multi-faceted, often complex pain syndrome in children and adolescents. Chronic daily headache may be primary or secondary. Chronic migraine and chronic tension-type are the most frequent subtypes. Chronic daily headache is co-morbid with adverse life events, anxiety and depressive disorders, possibly with other psychiatric disorders, other pain syndromes and sleep disorders; these conditions contribute to initiating and maintaining CDH. Hence, early management of episodic headache and treatment of associated conditions are crucial to prevention. There is evidence for the benefit of psychological therapies, principally relaxation and cognitive behavioral, and promising information on acupuncture for CDH. Data on drug treatment are based primarily on open label studies. The controversies surrounding $\mathrm{CDH}$ are discussed and proposals for improvement presented. The multifaceted nature of $\mathrm{CDH}$ makes it a good candidate for a multi-axial classification system. Such an approach should facilitate biopsychosocial management and enhance consistency in clinical research.
\end{abstract}

RÉSUMÉ: La céphalée quotidienne chronique chez les enfants et les adolescents, un syndrome à multiples facettes. La céphalée quotidienne chronique (CQC) est un syndrome douloureux à multiples facettes qui est souvent complexe chez les enfants et les adolescents. La céphalée quotidienne chronique peut être primaire ou secondaire. La migraine chronique et la céphalée de tension chronique sont les sous-types les plus fréquents. La CQC est une comorbidité des incidents fâcheux de la vie, de l'anxiété et des troubles dépressifs, possiblement liée à d'autres troubles psychiatriques, syndromes douloureux et troubles du sommeil. Ces états contribuent à amorcer et à maintenir la CQC. Le traitement précoce de la céphalée épisodique et le traitement des comorbidités est donc crucial pour la prévention. Certaines données démontrent un bénéfice des psychothérapies, principalement de la relaxation et de la thérapie cognitivo-comportementale, et l'acuponcture pour le traitement de la CQC semble prometteuse. Les données sur le traitement médicamenteux sont basées principalement sur des études ouvertes. Nous discutons des controverses entourant la CQC et des moyens proposés pour améliorer son traitement. Le fait que la CQC possède de multiples facettes fait d'elle un bon candidat à un système de classification à plusieurs axes. Une telle approche devrait faciliter la prise en charge biopsychosociale et rehausser la cohérence dans le domaine de la recherche clinique.

Can. J. Neurol. Sci. 2010; 37: 769-778

In 1982, Mathew et al first used the term "chronic daily headache" (CDH) to describe headaches that occurred almost daily in adults. ${ }^{1}$ Twelve years later, Holden et al published the first report on children with $\mathrm{CDH}^{2}$ Since then, there have been at least 21 reports globally. ${ }^{3-23}$ Cumulative knowledge suggests that $\mathrm{CDH}$ is not only a common chronic pain syndrome in children (the term will be used to include adolescents), but also a multi-faceted, and often complex one. The appreciation of the many aspects of $\mathrm{CDH}$ is pivotal to clinical research and management, and is the thrust of our review.

\section{DEFINITIONS AND ClASSIFICATION: THE CONTINUING CONTROVERSY}

\section{Background}

In the almost 30 years since the original description, $\mathrm{CDH}$ continues to evoke passionate debate. Globally accepted criteria are still lacking. ${ }^{24-26}$ As a consequence, it is difficult to compare studies, undertake meta-analysis or assess epidemiological data.

Chronic daily headache was not addressed in the first International Classification of Headache Disorders [ICHD-I] developed by the International Headache Society [IHS]. ${ }^{27}$ Therefore, Silberstein et al proposed a classification scheme for "daily and near-daily headaches." 28 Wöber-Bingöl et al and Nappi et al supported the need to improve the classification for CDH. ${ }^{9,29}$ These views were countered with the argument that virtually all chronic headache $(\mathrm{CH})$ patients could be classified using ICHD-I. ${ }^{30}$ Welch and Goadsby emphasized that $\mathrm{CDH}$ encompassed a group of headache disorders, either primary or secondary, characterized by a "high frequency of headache"; they felt that the term $\mathrm{CDH}$ had clinical utility, and that a classification of $\mathrm{CDH}$ could be accommodated in the appendix of the main ICHD. ${ }^{31}$ Chronic daily headache was not considered

From the Department of Pediatrics, Division of Pediatric Neurology (SSS), University of Saskatchewan, Saskatoon, Saskatchewan, Canada; Department of Neurology (SJW),

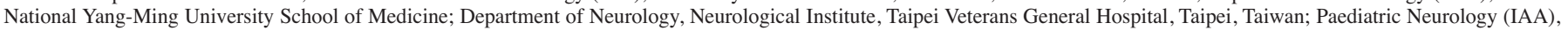

Stirling Royal Infirmary, Stirling; Royal Hospital for Sick Children, Glasgow; University of Dundee, UK; Pediatrics and Neurology (ADH), University of Cincinnati, College of

Medicine, Cincinnati Children's Hospital Medical Center. Cincinnati, Ohio; Palm Beach Headache Center (PW), Premiere Research Institute, Palm Beach Neurology, Nova

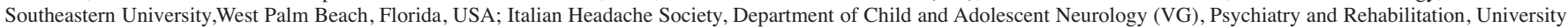

of Rome "La Sapienza," Roma, Italy; Department of Child and Adolescent Neuropsychiatry (CWB), University of Vienna, Wien-Vienna, Austria.

Received January 11, 2010. Final Revisions Submitted May 10, 2010.

Correspondence to: Shashi S. Seshia, Department of Pediatrics (Division of Pediatric Neurology), University of Saskatchewan, Saskatoon, Saskatchewan, S7N 0W8, Canada 
in ICHD-II. ${ }^{32}$ However, CDH was discussed subsequently by the Headache Classification Committee; they advised that $\mathrm{CDH}$ should not be used as a diagnostic entity, chronic headache $(\mathrm{CH})$ being preferred as the umbrella designation, ${ }^{33}$ an opinion challenged by Solomon. ${ }^{34}$ Despite the recommendation of the Headache Classification Committee, $\mathrm{CDH}$ is more widely used than $\mathrm{CH}$ and entrenched globally in the pediatric and adult literature, strengthening the argument for its formal adoption.

\section{Definitions and criteria}

'Chronic' has been defined inconsistently in ICHD-II. ${ }^{32} \mathrm{We}$ suggest that all subtypes of $\mathrm{CDH}$ be defined unambiguously as headache occurring $\geq 15$ days a month for $\geq 3$ months. ${ }^{20,26,34}$

Silberstein et al required that the average duration of headache be $>4$ hours/day untreated, while acknowledging that this criterion was arbitrary. ${ }^{28}$ Headache duration in $\mathrm{CDH}$ forms of the trigeminal autonomic cephalalgias (TACs) may be $<4$ hours/day. ${ }^{31}$ Hence, the suggestion that the duration criterion be reassessed has merit and needs to be explored further, ${ }^{26}$ especially since duration may influence diagnosis and management.

\section{Classification of CDH}

Chronic daily headache in children can be sub classified, using the ICHD frame-work [Table; appendix table] into primary (Codes 1-4) and secondary (Codes 5-12) types. ${ }^{11,14,15,17,19,20,27,32}$ The provisos for the diagnosis of any of the primary headache disorders include the caveat: "History and physical and neurological examinations do not suggest any of the disorders listed in groups $5-12 \ldots$ or (such disorders are) ruled out by appropriate investigations..." 32

Four issues that are the subject of continuing debate will be discussed.

\section{Transformed migraine}

Transformed migraine was proposed as a CDH subtype by Silberstein et al. ${ }^{28}$ As Mathew et al initially pointed out, transformed and transformation reflect change or evolution over a period of time from intermittent or episodic headache to CDH. ${ }^{1,35}$ We suggest that transformed not be used to describe type; rather, a particular $\mathrm{CDH}$ subtype, such as chronic migraine (CM), could be transformed or new-onset.

\section{Chronic migraine (Appendix code 1.5.1)}

The revised criteria for CM are currently as follows: ${ }^{33}$

A. Headache (tension-type and/or migraine) on $\geq 15$ days per month for at least three months,

B. Occurring in a patient who has had at least five attacks fulfilling ICHD-II criteria for (code1.1) migraine without aura, C. On $\geq 8$ days per month for at least three months headache has fulfilled $\mathrm{C} 1$ and /or $\mathrm{C} 2$ below,

(1) Has met criteria for migraine without aura as outlined in ICHD-II, and (2) Treated and relieved by triptan(s) or ergot before the development of $\mathrm{C} 1$.

D. No medication-overuse (as defined under code 8.2) and not attributed to another causative disorder.

The revised (ICHD-IIR) criteria for CM have been reviewed critically, and the requirement for a response to triptans or ergot
(C1) and the absence of medication- overuse for diagnosis (D) questioned. ${ }^{24}$ The assimilation of tension-type headache (TTH) within CM (Criterion A above) has also been challenged. ${ }^{20,25,26,34}$ Some of us favor the ICHD-IIR criteria for CM; others feel that until there is definite evidence to support that position, $\mathrm{CDH}$ with features of both migraine and TT should be classified as 'mixed' chronic migraine-chronic tension-type headache (CMCTTH). ${ }^{20,26}$ The 'gray zone' of $\mathrm{CDH}$ with features of both migraine and TTH needs further study. One practical solution to this impasse is to divide CM into two subforms: (i) CM solely with migraine features and (ii) CM with associated TTH features, as proposed by Solomon. ${ }^{34}$

\section{New daily-persistent headache (NDPH; code 4.8)}

New daily-persistent headache (NDPH) is coded as a separate primary headache type although the criteria, which were likely arbitrarily developed, are similar to those of CTTH. The ICHDII criteria for NDPH require (i) that onset or rapid development be "clearly and unambiguously recalled," and (ii) history, physical and neurological examination should not suggest secondary headache disorders coded under 5-12. ${ }^{32}$ The onset of NDPH was associated with infections or minor head injuries in one study ( $43 \%$ and $23 \%$ of 40 subjects, respectively) ${ }^{36}$ hence, the designation of NDPH exclusively as a primary headache disorder is questionable. Furthermore, migraine features were common in children with NDPH in another report. ${ }^{37}$ For these reasons and because, 'new daily' reflects a process that is the opposite of 'transformation', we suggest that the concept of NDPH be revisited in the next version of ICHD. Headaches should be classified by characteristics, an approach used by the IHS for almost all of the headache groups, types and subforms, not by mode of onset or evolution.

Medication-overuse headache (Code 8.2 and appendix 8.2) 32,33

The designation of medication-overuse headache $(\mathrm{MOH})$ as a separate headache type remains controversial and a source of considerable confusion. ${ }^{24,38}$ The criteria for $\mathrm{MOH}$ are empirical and adult oriented..$^{32,33}$ In one study on TTH, the use of analgesics and ergotamine preparations was uncommon in children compared to adults. ${ }^{9}$ Most pediatric studies suggest that the incidence of $\mathrm{MOH}$ is relatively low, although there are a few

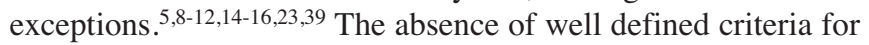
children may explain some of the differences between studies, although selection bias and geography may also play a role. Hence, pharmacologically based criteria are needed for children. ${ }^{8}$ Medication-overuse may reflect addictive behavior. ${ }^{40}$ Medication-overuse should be considered a potential co-morbid risk with $\mathrm{CDH}$, one that can contribute to transformation and persistence, and may not warrant listing as a specific entity.

\section{EPIDEMIOLOGY}

The prevalence of $\mathrm{CDH}$ across the entire pediatric age spectrum is unknown as population studies have been based on schoolchildren. Precise comparisons between studies are not possible because of potential methodological differences. The prevalence of $\mathrm{CDH}$ was reported as $0.9 \%$ from Scotland, ${ }^{41} 1.5 \%$ from Sweden, ${ }^{42} 7.8 \%$ from China, ${ }^{43} 1.5 \%$ from Taiwan ${ }^{16}$ and $1.68 \%$ from Brazil ${ }^{22}$, respectively. The prevalence for CTTH was $0.1 \%$ in Sweden and $5.9 \%$ in Turkey respectively. ${ }^{42,44}$ The 
prevalence in both preadolescence and adolescence is two to three fold higher in girls than in boys. ${ }^{16,22}$

In a headache clinic based study, 105 (6.5\%) of 1598 children were $<6$ years-of-age; of these 105 , five $(4.8 \%)$ had $\mathrm{CDH}^{13}$ About one in three attending four pediatric headache clinics suffered from $\mathrm{CDH} .{ }^{4,5,8,20}$

\section{Genetics}

There are three aspects to the genetics of $\mathrm{CDH}$ : (i) the genetics of the primary headache disorder (Codes 1-4) that has become $\mathrm{CDH}$, (ii) the genetic propensity for developing $\mathrm{CDH},{ }^{45}$ and (iii) the role of genetic factors in the neurobiological processes underlying central and peripheral sensitization responsible for chronification. The genetics of TTH, including CTTH, has been discussed recently. ${ }^{46}$ The genetics of $\mathrm{CH}$ has been discussed eloquently by Montagna et al; ${ }^{47}$ readers are directed to their paper, as a brief summary here will not do justice to the subject. In one study, 11 (16\%) of 70 children with $\mathrm{CDH}$ had a family history of $\mathrm{CDH}$ in first degree relatives. ${ }^{20}$ There are no data to help separate the roles of genetic influence and environment in this situation. The genetics of $\mathrm{CDH}$ in children needs further study.

\section{Associations (POSSIBLY CO-MORBID CONDITIONS)}

A number of conditions, especially psychiatric, associate with primary $\mathrm{CDH}$, suggesting that it is a syndrome with many facets. Their recognition is essential for management.

\section{Anxiety and depressive disorders}

Several publications have referred to the association between $\mathrm{CDH}$ on the one hand and anxiety and mood (specifically depressive) disorders on the other. ${ }^{1,6-8,11,12,17,18,20}$ In a community based study of 12 to 14-year-old school children, almost half of the 121 subjects with $\mathrm{CDH}$ had at least one psychiatric disorder; depressive disorders were found in 30\% (36 of 121) and anxiety disorders in $36 \%$ (43 of 121); additionally $20 \%$ (24 of 121) had high "current" suicidal scores. ${ }^{18}$ These figures were much higher than those in the age matched general population. Migraine, especially migraine with aura, and female gender increased the risk of the association. In a population-based study on individuals older than ten years in rural Brazil, psychiatric comorbidities were found in two-thirds of those with $\mathrm{CDH}^{48}$

\section{Other psychiatric disorders}

Mathew et al found an association between $\mathrm{CDH}$ in adults and "hysteria."1 About $20 \%$ of 37 children with $\mathrm{CDH}$ in one study had "histrionic traits, as characterized by la belle indifference, in which symptoms described far outweighed disability seen by the family." 3 The diagnosis of somatoform disorder, factitious disorder and malingering in children with $\mathrm{CDH}$ was discussed in another report; ${ }^{20}$ differentiation between these three entities even with DSM-IV-TR criteria, ${ }^{49}$ is very dependent on the history and susceptible to subjective clinical opinion. ${ }^{20}$ In a third, symptoms of anxiety, depression and somatization were more common in children with $\mathrm{CDH}$ than in controls. $^{39}$

In a fourth study, children with $\mathrm{CDH}$ and school phobia were found to have a significantly higher incidence of psychiatric disorders than those without school phobia; the psychiatric disorders included adjustment, anxiety and conversion. ${ }^{50}$

\section{Family history of psychiatric disorder}

There is a higher incidence of psychiatric disorders in the parents of children with migraine compared to that in children with non-migraine headache. ${ }^{51} \mathrm{~A}$ family history of anxiety disorder in first degree relatives was found in $7 \%(\mathrm{~N}=5)$, and of depressive disorder in $31 \%(\mathrm{~N}=22)$ of 70 children with $\mathrm{CDH}$; these were not stratified by headache type. ${ }^{20}$ Such illnesses in close family members were described as important stressors for child and family, ${ }^{8,20}$ adding to the complexity of $\mathrm{CDH}$.

\section{Disorders of sleep}

Sleep disorders occur very frequently in adult headache subjects and morning headaches may be a clue to their presence. ${ }^{52-54}$ Anxiety and depression may not entirely explain sleep disorders in adult migraineurs. ${ }^{55}$ Several studies, the majority based on sleep questionnaires, including some that were population based, have drawn attention to the association between sleep disorders and childhood headache. ${ }^{56-62}$ The association was stronger with migraine than TTH, although those with TTH (including CTTH) may not have been adequately represented. From polysomnographic studies, Vendrame et al found an association between TTH and bruxism; those with severe or CM had disrupted sleep architecture with reduced rapid eye movement and slow-wave sleep. ${ }^{59}$ The data support the possibility of a close relationship between sleep and headache disorders. Twenty-three percent $(\mathrm{N}=16)$ of 70 children with $\mathrm{CDH}$ complained of disturbed sleep that was not necessarily related to headache but information was insufficient to identify associated sleep disorders. ${ }^{20}$ A systematic study for sleep disorders/disturbances in children with $\mathrm{CDH}$ is needed.

\section{Other pain syndromes}

Headache and other pain syndromes may be co-morbid in children and adults. ${ }^{63}$ The issue needs prospective study as data specific for $\mathrm{CDH}$ is lacking.

\section{Obesity}

There is an association between obesity and progression of episodic migraine to CM but not between obesity and TTH, in adults. ${ }^{64}$ The incidence of obesity in two pediatric headache clinic based studies, one on those with $\mathrm{CDH}$, was not different from that in the general population; subjects were not stratified by gender. ${ }^{20,65}$ Overweight females had a near four fold excess risk of headache when compared to normal-weight girls; there was no relationship between weight and headache in males. ${ }^{66}$

\section{Precipitating AND CONTRIbutory Factors}

Clinical observations have shown that several factors may precipitate, contribute to transformation and maintain $\mathrm{CDH}$. Their identification and management is also essential.

\section{Stressors/adverse life events/life changes}

These terms are often used interchangeably. They may be positive or negative, minor hassles or major events. Stresses may 
lead to post-traumatic stress disorder. Stress disorders are listed under anxiety disorders in DSM-IV-R. ${ }^{49}$ Stressors, frequently multiple, contributed to transformation in forty to fifty percent of children with $\mathrm{CDH}$ and were also considered important in maintaining $\mathrm{CDH} .^{4,7,8,20,23}$ For children, stresses are often family/home related, peer related or school related; bullying is an important school related stressor. ${ }^{8}$ The risk of frequent headache in five year olds was increased by low socio-economic status and increasing number of leisure activities. ${ }^{67} \mathrm{~A}$ higher incidence of divorce in the parents of children with TTH has been noted. ${ }^{68}$

There was a significant association between adolescent $\mathrm{CDH}$ and childhood adversity, specifically parental divorce and physical abuse, in a community based study; the authors did not find examples of sexual abuse but commented on the difficulty in identifying such victims ${ }^{69}$ Childhood maltreatment (physical abuse, sexual abuse, emotional abuse, and physical neglect) may be a risk factor for $\mathrm{CDH}$ in adults and is often associated with other pain syndromes, depressive and anxiety disorders..$^{70,71}$ The prevalence of specific adverse events is likely to be country and community specific. Greater attention has to be paid to the possibility of maltreatment in children with $\mathrm{CDH}$ and country/community specific epidemiological studies are needed.

\section{Head/neck trauma}

Minor head injury, especially sports related, is often a cause of NDPH. ${ }^{8,10,36}$ The cause may be overlooked unless history is sought. We are unaware of studies assessing the relationship between neck trauma and $\mathrm{CDH}$ in children. Chronic posttraumatic headache after head injury, whiplash and other head or neck trauma is discussed under code 5 of ICHD-II. ${ }^{32}$

\section{Other}

Sleep deprivation, fatigue, irregular sleep habits, hunger, noise and bright lights often contribute to CDH. Caffeine is considered a risk factor in adults, ${ }^{1,72}$ and is very like one in children.

\section{NeUROBIOLOGY}

The neurobiology of TTH, including CTTH, has been discussed recently. ${ }^{46}$ Chronic daily headache generally evolves from intermittent headache. The transformation to and the features of $\mathrm{CDH}$ can be explained by central and peripheral sensitization (the former more than the latter); changes in the trigeminal system, altered neuroimmunity and compromise to endogenous 'analgesia systems' (pain transmission and modulation) are considered central to the process; stress, anxiety and depressive disorders, and chronic analgesia exposure likely act through these mechanisms. ${ }^{73-77}$ The putative mechanisms behind sensitization are likely common to all subtypes, although most investigators have focused on CM.

\section{Clinical features and Subtypes of Chronic daily HEADACHE}

\section{Primary subtypes (Codes 1-4)}

Headache is generally bilateral, mainly frontal. $5,10,20$ However, consistently unilateral headache has been reported in $3 \%$ to $16 \%$ of children with $\mathrm{CDH}$, in some series. ${ }^{10,20,78}$ The majority of primary $\mathrm{CDH}$ disorders are transformed from intermittent headache. Transformation occurred in $78 \%$ of 630 patients in the series of Mathew et al. ${ }^{35} \mathrm{~A}$ similar percentage has been reported in children. $6,8,10,20$

Chronic migraine, CTTH, mixed CM and CTTH, in variable proportion, have constituted the most frequent subtypes of primary $\mathrm{CDH}$ in clinic based studies..$^{3,5-12,16,19,20}$ In an adolescent community based study, the relative frequencies for $\mathrm{CM}$ and CTTH were $7 \%$ and $66 \%$ respectively $(\mathrm{N}=122)$ but $59 \%$ of those with CTTH also had migraine attacks. ${ }^{16}$ Of note, the prevalence of CM increased (from $7 \%$ to $23 \%$ ) when the revised criteria for $\mathrm{CM}$ were applied. ${ }^{17}$ Even in those with preceding migraine, migraine characteristics often decline and TTH characteristics become prominent when $\mathrm{CDH}$ develops.5,79 Conversely, migraine features may increase as $\mathrm{CDH}$ remits. ${ }^{17}$ These patterns in some (but not all) with $\mathrm{CDH}$ further compounds the challenges of 'lumping' or 'splitting' CDH into CM, CTTH and mixed CM and CTTH subtypes respectively.

Unilateral headache, most striking over the orbital, supraorbital or temporal regions, with associated cranial autonomic features strongly suggests a TAC (Code 3) or HC (Code 4.7); response to indomethacin is considered essential under ICHD-II for diagnosing HC. ${ }^{32}$ However, not all those with the clinical phenotype of $\mathrm{HC}$ respond to indomethacin. ${ }^{80}$ The relative frequency of TAC and $\mathrm{HC}$ in children when compared to CM, CTTH or mixed CM and CTTH, must be extremely low; there were no cases in one population study conducted over eight years to date. ${ }^{16,17,21}$

Clinical features of psychological and psychiatric comorbidity are often present. Although headache may be constant and even severe or disabling through the day, they are usually not described as a problem during sleep.,20 When sleep is disturbed, then the possibility of associated mood, anxiety and sleep disorders must be considered.

\section{Secondary subtypes (Codes 5-12)}

In one study, $10 \%$ of seventy children with $\mathrm{CDH}$ had a secondary cause, the majority after minor concussion (code 5.6.2) ${ }^{20}$ International Classification of Headache Disorders-II provides diagnostic criteria for the secondary subtypes. ${ }^{32}$

Chronic daily headache, $\mathrm{CM}$ in most reports, may associate with idiopathic intracranial hypertension (IIH; code 7.1.1) without papilledema. ${ }^{81-85}$ Idiopathic intracranial hypertension may or may not be the sole cause of $\mathrm{CDH}$ in these cases. Chiari malformation type I (code 7.7) may cause $\mathrm{CDH} .{ }^{32,86}$

\section{RATING DISABILITY AND QUALITY OF LIFE}

PedMIDAS was designed to assess the disability of children with migraine and can be used in those with with $\mathrm{CM} .{ }^{87}$ It was not intended for TTH; hence, we have reservations about its application in $\mathrm{CTTH} .{ }^{46}$ Universally accepted rating scales and quality of life measures are needed ${ }^{88}$

\section{DiFFERENTIAL DIAGNOSIS}

The important elements in history, physical examination, differential diagnosis and the red flags for TTH, including CTTH, have been discussed. ${ }^{46}$ They apply to CDH. Intractable $\mathrm{CDH}$ and persistent unilaterality of headache are additional red flags. Occipital or sub-occipital location and worsening with 
coughing or Valsalva maneuver may suggest Chiari malformation type I. ${ }^{32,86}$ Aggravation in the upright position with improvement by lying down may point to an intracranial hypotension syndrome; other associated clinical features include neck stiffness, tinnitus, hypacusia (Codes 7.2.2; 7.2.3). ${ }^{32}$

The possibility of IIH without papilledema must be considered under the following circumstances: (i) Intractable $\mathrm{CDH}$, (ii) tinnitus or noise in the head as a symptom (important to seek this information), particularly in the presence of obesity, although subjects may be of normal weight. ${ }^{32,81-85}$ A detailed ophthalmologic examination, not only testing of visual acuity, examining fundii and assessing for venous pulsations but also blind spot charting, visual field assessment and contrast sensitivity, must be done in all those suspected of having IIH.

\section{INVESTIGATIONS}

The majority of children with $\mathrm{CDH}$ will not need specific investigation, especially neuroradiological..$^{8,20,89,90}$ If secondary $\mathrm{CDH}$ is suspected, magnetic resonance imaging of the head including magnetic resonance angiography and venography is preferred to computed tomography not only due to potential risks of radiation from computed tomography but also because of the broader range of information that is provided. ${ }^{46}$ The cervical spine should be included in the study to identify a Chiari malformation. Continuous cerebrospinal fluid pressure monitoring may be more helpful than an isolated measurement if IIH or low cerebrospinal fluid pressure syndromes are suspected..$^{46,91}$

Other investigations will be determined by the differential diagnosis entertained.

\section{Management}

There may be regional or personal differences in the availability and use of specific non-pharmacologic and pharmacologic treatments. Therefore, the suggestions that follow should be tailored to the individual. The general principles are similar to those outlined for TTH, ${ }^{46}$ and will not be detailed. The first step is to identify and treat the factors, including lifestyle issues that have precipitated and contributed to $\mathrm{CDH}$. Chronic daily headache, especially primary, must be handled in a multidisciplinary biopsychosocial manner. Immediate family members have to be involved in the assessment of stressors or illnesses in them, as these may contribute to the child's $\mathrm{CDH}^{8,20}$ The team can determine if stressors and associated psychiatric disorders should be treated before or in conjunction with pharmacologic management of pain. The relative contributions to impaired quality of life by headache and associated conditions are central to decision making. Analgesics are frequently ineffective in $\mathrm{CDH}$. When there has been overuse, gradual withdrawal of the offending agent should be done.

\section{Psychological therapies}

There is good evidence for the effectiveness of psychological therapies, especially relaxation and cognitive behavioral, in reducing severity and frequency of $\mathrm{CH} .{ }^{92}$ Hence, if readily available, such treatment should be offered as an alternative to drugs. Space does not permit a detailed description of psychological interventions.

\section{Other non-pharmacologic}

Needling acupuncture was found superior to sham acupuncture and medication in improving $\mathrm{CH}$ in adults. ${ }^{93}$ Laser acupuncture has been reported to be effective in children with headache. ${ }^{94}$ Therefore, acupuncture is another potential nonpharmacologic treatment for $\mathrm{CDH}$ in children but further studies to firmly establish efficacy are needed.

\section{Pharmacologic}

When considered necessary because of the impact of pain on quality of life, the specific choice of drug is dependent not only upon the subtype of $\mathrm{CDH}$ but also the presence of associated conditions such as anxiety, depressive or other psychiatric disorders. The relatively high placebo effect in children makes assessment of benefit difficult. ${ }^{95}$ Most if not all of the drugs used are off-label, and the evidence for benefit is based on open label studies. Doses are empiric, since there are no studies based on doses calculated by body weight or surface area. The role of pharmacogenetic factors has not been addressed. Three of 122 participants with $\mathrm{CDH}$ in a community based study received treatment; only $25 \%$ of the total had $\mathrm{CDH}$ after two years of follow-up; ${ }^{17}$ this 'natural history' must be factored into the outcomes of any treatment trial.

With these provisos, dihydroergotamine and metoclopromide given intravenously in the out-patient or emergency room setting may ameliorate or abolish the pain of $\mathrm{CTTH}, \mathrm{CM}$ or mixed CTTH-CM, even in a single dose.

Chronic tension-type headache and mixed chronic migrainechronic tension-type headache

The management has been discussed recently. ${ }^{46}$

\section{Chronic migraine}

We have no evidence for the efficacy of triptans once a $\mathrm{CDH}$ pattern is established. Open label data suggest a role for intravenous valproic acid (VPA) in adults. ${ }^{96}$ We are not aware of information in children. Chronic migraine remitted in seven adolescents given dihydroergotamine, dexamethasone and hydroxyzine parenterally once a week for three weeks. ${ }^{97}$

We are unaware of evidence for the benefit of oral cyproheptadine, flunarizine, propanolol or riboflavin but these were considered effective in one clinic based study. ${ }^{10}$ Riboflavin and Coenzyme Q10, singly or in combination, are worthy of trial because they are innocuous. Amitryptiline, gabapentin and topiramate have a beneficial effect on pain and can be used orally for CM in the same manner as for frequent episodic TTH and CTTH; ${ }^{46,98}$ they are our other choices in this situation. Topiramate is preferred in obese subjects. Limitations to the use of VPA include: potential for weight gain, possible risk of polycystic ovary syndrome and teratogenicity. Hence, VPA may not be a suitable choice for adolescent females who constitute a high proportion of those with $\mathrm{CDH}$. Improvement with any prophylactic drug is often delayed for about a month, and in some, the $\mathrm{CDH}$ then resolves. Treatment is then generally continued for a three month headache period before gradual discontinuation, a practice for which there is no evidence. 


\section{Hemicrania continua}

A trial of indomethacin should be given to any child who presents with unilateral headache. ${ }^{99}$ Indomethacin has troublesome side-effects, and alternatives include gabapentin and topiramate. ${ }^{100}$ Other non-steroidal anti-inflammatory drugs may also be effective if these have not already been tried.

\section{In-patient Management}

In-patient management in an age appropriate facility is generally reserved for children who have high pain intensity, are disabled by pain (i.e. unable to participate effectively in school or extracurricular activities), who are suspected of having severe anxiety or mood disorder, or in whom significant adverse social factors are suspected. The protocol for management is similar to that outlined for CTTH. ${ }^{46}$ Secondary causes must be excluded in those with intractable $\mathrm{CDH}$.

\section{Other treatments for chronic daily headache}

Mexilitene may be useful in adults with refractory $\mathrm{CDH} ;{ }^{101}$ we are unaware of data in children. Botulinum toxin type A may be an effective option in children with $\mathrm{CDH}$, and the authors felt that a controlled trial was warranted..$^{102}$

\section{OUTCOME}

Outcome data are limited and confounded by the differences in length of follow-up and criteria for improvement. The ideal outcome is the headache-free state. In one communication, headaches resolved completely and were not considered a management issue by $48(68 \%)$ of 70 children with $\mathrm{CDH}$; however, $5(10 \%)$ of the 48 relapsed within the three-year follow-up period, four of the five being girls ${ }^{20}$ In another, over a ten-year follow-up, $86.5 \%$ (32/37) were improved, $8 \%(3 / 37)$ were worse, and $5 \%(2 / 37)$ were unchanged; ${ }^{103}$ the authors felt that the comprehensive biopsychosocial approach provided in their centre contributed to the results. From an adolescent community based study, at the end of eight years, $11 \%$ (11 of 103) were headache free, $27 \%$ (28 of 103) still had moderate to severe headache disability and $12(11 \%)$ continued to meet criteria for $\mathrm{CDH}^{21}$ Prognosis may be less favorable in girls, in those with migraine, those with medication-overuse, those with $\mathrm{CDH}$ onset $<13$ years-of-age, $\mathrm{CDH}$ duration $\geq 2$ years, and those with associated psychiatric disorders. ${ }^{11,17,20,21,104}$ Fifty-nine (59\%) of 100 adults with $\mathrm{CDH}$ recalled having headaches as children. ${ }^{105}$ Thirteen percent of adults ( 8 of 60 ) in another study, recalled onset of $\mathrm{CDH}$ in childhood. ${ }^{106}$ These data suggest that $\mathrm{CDH}$ may not remit or may only improve partially in a clinically significant number of children; ${ }^{104-107}$ therefore, those at high risk for chronicity (see above) should be targeted for early "aggressive" intervention. ${ }^{104}$ Additionally, children with $\mathrm{CDH}$ should be followed into late adult life to better define long term outcome; data bases such as those used in Taiwan provide a model to achieve this end.

\section{A multi-AXial APPROACH TO CDH? ${ }^{20,26}$}

The information presented shows that primary $\mathrm{CDH}$ is a multi-factorial, often complex syndrome (Figure). Hence, it would lend itself well to a multi-axial system of classification such as that used in Psychiatry. ${ }^{49} \mathrm{~A}$ tentative multi-axial classification has been proposed [Table]. ${ }^{20,26}$ There is merit in exploring and refining such a classification for $\mathrm{CDH}$ in particular and headache disorders in general.

\section{Conclusions}

With a prevalence of at least $1 \%$ in school children, $\mathrm{CDH}$ is an important pain syndrome in childhood. A clinically significant percentage continues to have frequent headache and $\mathrm{CDH}$ into adult life. In the preface to ICHD-II, Professor Olesen wrote, "It is important for any field of medicine to have a generally-accepted classification that is used throughout the world." 32 Hence, the absence of universally acceptable nomenclature and classification for $\mathrm{CDH}$ needs to be rectified. Many conditions, particularly psychiatric and psychological, are co-morbid with and contribute to primary CDH. Therefore, a multi-axial approach may improve management..$^{20,26} \mathrm{~A}$ multiaxial classification may also enhance uniformity in the clinical, education and research settings, ${ }^{49}$ a key goal of the IHS. A classification for $\mathrm{CDH}$ could be incorporated as an appendix to

\section{Table: Proposed axes for classification of $\mathrm{CDH}^{20,26}$}

Axis I: Main headache Group (CDH; Type Primary or Secondary)

Axis II: Subtype/s (ICHD codes)*

Primary

Chronic migraine (CM; 1.5.1): (i) Solely with migraine features (ii) with associated TTH features

Chronic tension-type headache (CTTH; 2.3)

Chronic cluster (3.1.2)

Chronic paroxysmal hemicrania $(\mathrm{CPH} ; 3.2 .2)$

Hemicrania continua (HC; 4.7)

New daily-persistent headache (NDPH; 4.8)

Secondary (specify diagnosis/code)

Axis III: Associated medical conditions (examples: Psychiatric disorders such as anxiety or depression; other pain syndromes; obesity etc)

Axis IV: Contributory factors (examples: adverse life events: specify; concussion; analgesia-overuse; caffeine etc)

Axis V: Functional impairment (specify sphere of activity) $\dagger$ Axis VI: Pain Severity**

Multi-axial classification for CDH. Note: *Please see discussion in the text pertinent to the subtypes. $\dagger$ There may be dissociation of functional impairment for different activities. $* *$ Standardized universally accepted tools needed. We are grateful to Wiley-Blackwell \& Mac Keith Press (Publishers of Developmental Medicine and Child Neurology), and John Wiley \& Sons, Inc., (Publishers of Cephalalgia) for permission to adapt the Table from Table V in reference 20 and Table 1 in reference 26 respectively, the former being the original and the latter a reproduction. 


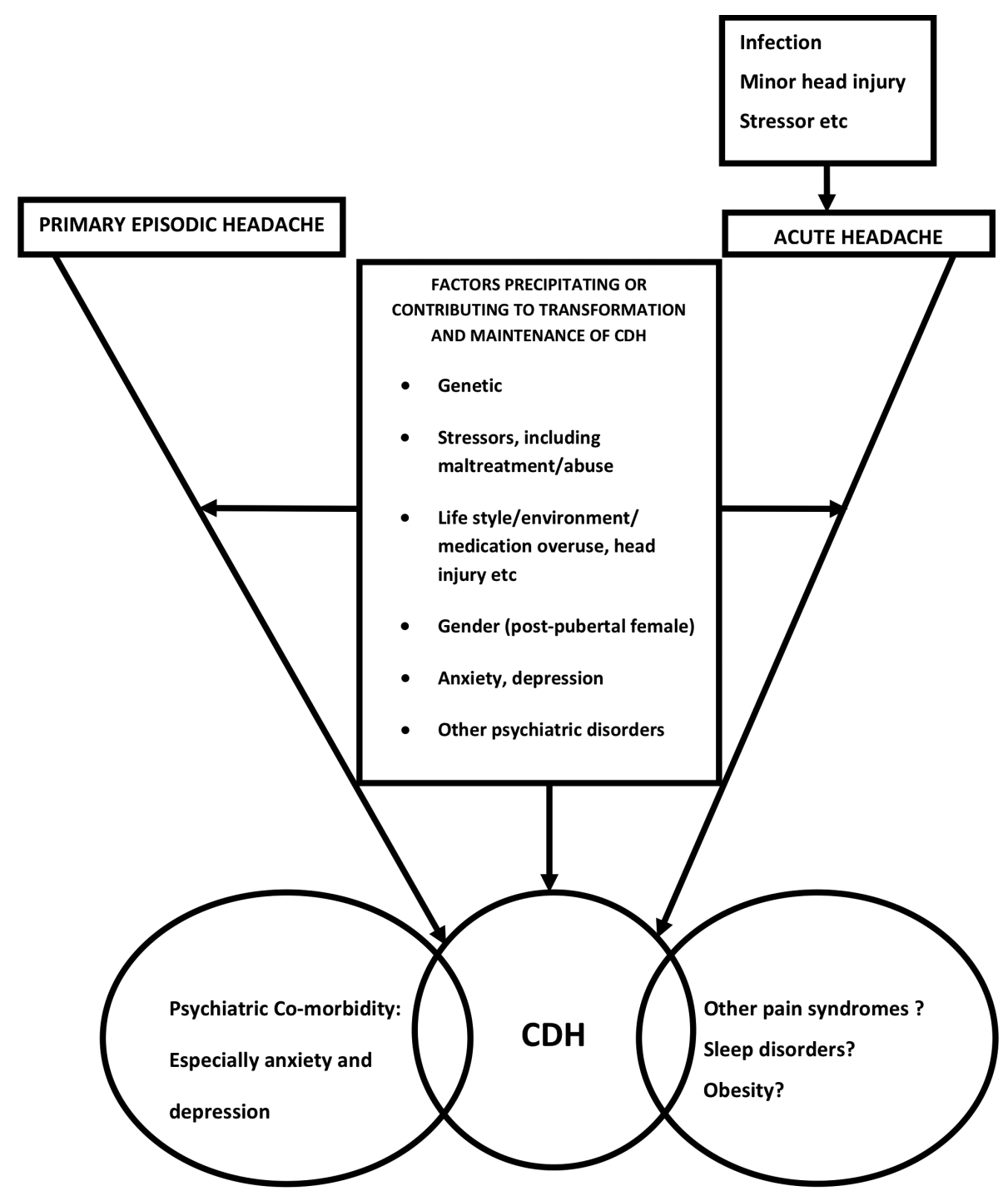

Figure: Multi-faceted nature of primary CDH (chronic daily headache). Please see text for details specific to the variables listed. The question mark ('?') after some variables reflects the uncertainty of information regarding their association with $\mathrm{CDH}$. Life style/environmental factors include: sleep deprivation, fatigue, noise, bright lights, caffeine, etc. The information on the transformation of primary episodic headache to $\mathrm{CDH}$ applies best to chronic migraine, chronic tension-type headache and mixed chronic migraine and tension-type. Acute headache may progress to new daily-persistent headache.

the main ICHD classification, as suggested by Welch and Goadsby. ${ }^{31}$

\section{ACKNOWLEDGEMENTS}

This paper is based on presentations given at the Pediatric headache course and the Pediatric headache session at the 14th Congress of the International Headache Society, September 1013, 2009, Philadelphia, USA. SSS thanks (i) Ms. Erin Watson of the Health Sciences Library, for assisting with retrieval of references, (ii) Dr. Carl von Baeyer, Emeritus Professor of Psychology and Associate in Pediatrics (both of the University of Saskatchewan), for reviewing the manuscript and suggesting improvements, (iii) Dr. Molly Seshia for formatting the figure, and (iv) Professor A. Srikiatkhachorn of Thailand for helpful discussions on neurobiological mechanisms.

\section{DEDICATION}

We dedicate this paper to the late Professor Giovanni Lanzi (formerly of Pavia, Italy), a pioneer in the discipline of Childhood and Adolescent Neuropsychiatry and in the field of Child Neurology, especially headache in children and adolescents. 


\section{Foot-Notes}

(i) Readers are advised to refer to current Pediatric Drug Dosage references specific to their population, for doses of drugs discussed and for information about toxicity, drug interactions etc. Some of the drugs mentioned may not be available in all countries.

(ii) The literature on adult $\mathrm{CDH}$ is vast. Only those pertinent to our review have been cited.

(iii) We have attempted to minimize duplication of information provided in reference number 46. The current review and reference 46 should be considered companion papers.

(iv) Depression (colloquial) and depressive disorder (DSM IV) have been used synonymously in this review.

\section{Appendix: Abbreviated ICHD-II classification ${ }^{32}$}

\author{
The primary headaches \\ 1. Migraine \\ 2. Tension-type headache \\ 3. Cluster headache and other trigeminal autonomic cephalagias \\ 4. Other primary headaches
}

\section{The Secondary headaches}

5. Headache attributed to head and/or neck trauma

6 . Headache attributed to cranial or cervical vascular disorder

7. Headache attributed to non-vascular intracranial disorder

8. Headache attributed to a substance or its withdrawal

9. Headache attributed to infection

10. Headache attributed to disorder of homoeostasis

11. Headache or facial pain attributed to disorder of cranium, neck, eyes, ears, nose, sinuses, teeth, mouth or other facial or cranial structures

12. Headache attributed to psychiatric disorder

Cranial neuralgias, central and primary facial pain and other headaches

13. Cranial neuralgias and central causes of facial pain

14. Other headache, cranial neuralgia, central or primary facial pain

Abbreviated ICHD-II classification. Numbers refer to code for headache group. Subtypes would be coded to the two digit level (example, 1.2 for migraine with aura), and subform at the three digit level (example, 1.5.1 for chronic migraine). Reproduced from reference 32 with permission of International Headache Society, to whom we are grateful. The classification is available for download without cost at http://www.ihs-classification.org/en/

\section{Disclosures}

None of the disclosures listed below is specific for this manuscript. SJW: Advisory boards: Allergan, Daichi-Sankyo, MSD and Pfizer, Taiwan. Speaking honoraria from Taiwan branches of Boehringer Ingelheim, Eli Lilly, Glaxosmithkline, Jensen-Cilag, Pfizer, and Wyeth. AH: Grant support: NIH, Endo Pharmaceuticals; Consulting support: Glaxosmithkline, MAP Pharma; Contracts: Merck, Glaxosmithkline. VG: Member advisory board on migraine for Merck Sharp and Dome (Italy). PW: Advisory Board/Consultant: Allergan, Glaxosmithkline, Merck, OrthoMcNeil, Shire; Speaker/Honoraria: Allergan, Frova, Glaxosmithkline and Merck; Grants/Research: Allergan, Eli Lilly, Glaxosmithkline, MAP, Novartis, Pfizer and Wyeth.

\section{REFERENCES}

1. Mathew NT, Stubits E, Nigam MP. Transformation of episodic migraine into daily headache: analysis of factors. Headache. 1982 Mar; 22(2): 66-8.

2. Holden EW, Gladstein J, Trulsen M, Wall B. Chronic daily headache in children and adolescents. Headache. 1994 Oct; 34(9): 508-14.

3. Gladstein J, Holden EW. Chronic daily headache in children and adolescents: a 2-year prospective study. Headache. 1996 Jun; 36(6): 349-51.

4. Abu-Arafeh I. Chronic tension-type headache in children and adolescents. Cephalalgia. 2001 Oct; 21(8): 830-6.

5. Hershey AD, Powers SW, Bentti AL, LeCates S, deGrauw TJ. Characterization of chronic daily headaches in children in a multidisciplinary headache center. Neurology. 2001 Apr 24; 56(8): 1032-7.

6. Koenig MA, Gladstein J, McCarter RJ, Hershey AD, Wasiewski W, Pediatric Committee of the American Headache Society. Chronic daily headache in children and adolescents presenting to tertiary headache clinics. Headache. 2002 Jun; 42(6): 491-500.

7. Esposito SB, Gherpelli JL. Chronic daily headaches in children and adolescents: a study of clinical characteristics. Cephalalgia. 2004 Jun; 24(6): 476-82.

8. Seshia SS. Chronic daily headache in children and adolescents. Can J Neurol Sci. 2004 Aug; 31(3): 319-23.

9. Wöber-Bingöl C, Wober C, Karwautz A, Schnider P, Vesely C, Wagner-Ennsgraber $\mathrm{C}$, et al. Tension-type headache in different age groups at two headache centers. Pain. 1996 Sep; 67(1): 53-8.

10. Moore AJ, Shevell M. Chronic daily headaches in pediatric neurology practice. J Child Neurol. 2004 Dec; 19(12): 925-9.

11. Galli F, Patron L, Russo PM, Bruni O, Ferini-Strambi L, Guidetti V. Chronic daily headache in childhood and adolescence: clinical aspects and a 4-year follow-up. Cephalalgia. 2004 Oct; 24(10): 850-8.

12. Chakravarty A. Chronic daily headache in children and adolescents: a clinic based study from India. Cephalalgia. 2005 Oct; 25(10): 795-800.

13. Raieli V, Eliseo M, Pandolfi E, La Vecchia M, La Franca G, Puma $\mathrm{D}$, et al. Recurrent and chronic headaches in children below 6 years of age. J Headache Pain. 2005 Jun; 6(3): 135-42.

14. Scalas C, Calistri L. Chronic daily headache in a paediatric headache centre. J Headache Pain. 2005 Sep; 6(4): 274-6.

15. Wiendels NJ, van der Geest MC, Neven AK, Ferrari MD, Laan LA. Chronic daily headache in children and adolescents. Headache. 2005 Jun; 45(6): 678-83.

16. Wang SJ, Fuh JL, Lu SR, Juang KD. Chronic daily headache in adolescents: prevalence, impact, and medication overuse. Neurology. 2006 Jan 24; 66(2): 193-7.

17. Wang SJ, Fuh JL, Lu SR, Juang KD. Outcomes and predictors of chronic daily headache in adolescents: a 2-year longitudinal study. Neurology. 2007 Feb 20; 68(8): 591-6.

18. Wang SJ, Juang KD, Fuh JL, Lu SR. Psychiatric comorbidity and suicide risk in adolescents with chronic daily headache. Neurology. 2007 May 1; 68(18): 1468-73. 
19. Cuvellier JC, Couttenier F, Auvin S, Vallée. The classification of chronic daily headache in French children and adolescents: A comparison between the second edition of the international classification of headache disorders and Silberstein-Lipton criteria. Neuropsychiatr Dis Treat. 2008 Feb; 4(1): 263-7.

20. Seshia SS, Phillips DF, von Baeyer CL. Childhood chronic daily headache: a biopsychosocial perspective. Dev Med Child Neurol. 2008 Jul; 50(7): 541-45

21. Wang SJ, Fuh JL, Lu SR. Chronic daily headache in adolescents: an 8-year follow-up study. Neurology. 2009 Aug 11; 73(6): 416-22.

22. Arruda MA, Guidetti V, Galli F, Albuquerque RC, Bigal ME. Frequent headaches in the preadolescent pediatric population: a population-based study. Neurology. 2010 Mar 16; 74(11): 903-8.

23. Cuvellier JC, Couttenier F, Joriot-Chekaf S, Vallée L. Chronic daily headache in French children and adolescents. Pediatr Neurol. 2008 Feb; 38(2): 93-8

24. Manack A, Turkel C, Silberstein S. The evolution of chronic migraine: classification and nomenclature. Headache. $2009 \mathrm{Sep}$; 49(8): 1206-13.

25. Manzoni GC, Torelli P. Chronic migraine and chronic tension-type headache: are they the same or different? Neurol Sci. 2009 May; 30 Suppl 1: S81-4

26. Seshia SS, Wober-Bingol C, Guidetti V. The classification of chronic headache: room for further improvement? Cephalalgia. 2009; In Press.

27. Classification and diagnostic criteria for headache disorders, cranial neuralgias and facial pain. Headache Classification Committee of The International Headache Society. Cephalalgia. 1988; 8 Suppl 7: 1-96.

28. Silberstein SD, Lipton RB, Solomon S, Mathew NT. Classification of daily and near-daily headaches: proposed revisions to the IHS criteria. Headache. 1994 Jan; 34(1): 1-7.

29. Nappi G, Granella F, Sandrini G, Manzoni GC. Chronic daily headache. How should it be included in the IHS classification? Headache. 1999 Mar; 39(3): 197-203.

30. Olesen J, Rasmussen BK. The International Headache Society classification of chronic daily and near-daily headaches: a critique of the criticism. Cephalalgia. 1996 Oct; 16(6): 407-11

31. Welch KM, Goadsby PJ. Chronic daily headache: nosology and pathophysiology. Curr Opin Neurol. 2002 Jun; 15(3): 287-95.

32. Headache Classification Subcommittee of the International Headache Society. The International Classification of Headache Disorders: 2nd ed. Cephalalgia. 2004; 24 Suppl 1: 9-160.

33. Headache Classification Committee, Olesen J, Bousser MG, Diener HC, Dodick D, First M, Goadsby PJ, et al. New appendix criteria open for a broader concept of chronic migraine. Cephalalgia. 2006 Jun; 26(6): 742-6.

34. Solomon S. New appendix criteria open for a broader concept of chronic migraine. Cephalalgia. 2007 May; 27(5): 469; author reply 469-70.

35. Mathew NT, Reuveni U, Perez F. Transformed or evolutive migraine. Headache. 1987 Feb; 27(2): 102-6.

36. Mack KJ. What incites new daily persistent headache in children? Pediatr Neurol. 2004 Aug; 31(2): 122-5.

37. Kung E, Tepper SJ, Rapoport AM, Sheftell FD, Bigal ME. New daily persistent headache in the paediatric population. Cephalalgia. 2009 Jan; 29(1): 17-22.

38. Sun-Edelstein C, Bigal ME, Rapoport AM. Chronic migraine and medication overuse headache: clarifying the current International Headache Society classification criteria. Cephalalgia. 2009 Apr; 29(4): 445-52.

39. Pakalnis A, Butz C, Splaingard D, Kring D, Fong J. Emotional problems and prevalence of medication overuse in pediatric chronic daily headache. J Child Neurol. 2007 Dec; 22(12): 1356-9.

40. Radat F, Creac'h C, Guegan-Massardier E, Mick G, Guy N, Fabre $\mathrm{N}$, et al. Behavioral dependence in patients with medication overuse headache: a cross-sectional study in consulting patients using the DSM-IV criteria. Headache. 2008 Jul; 48(7): 1026-36.

41. Abu-Arefeh I, Russell G. Prevalence of headache and migraine in schoolchildren. BMJ. 1994 Sep 24; 309(6957): 765-69.
42. Laurell K, Larsson B, Eeg-Olofsson O. Prevalence of headache in Swedish schoolchildren, with a focus on tension-type headache. Cephalalgia. 2004 May; 24(5): 380-8.

43. Zhang LM, Zhou SZ, Chai YM, Yang JD, Xue J, Liang J. Prevalence of chronic headache in Shanghai children and adolescents: a questionnaire-based study. Zhonghua $\mathrm{Er} \mathrm{Ke} \mathrm{Za}$ Zhi. 2007 Apr; 45(4): 262-6.

44. Ozge A, Bugdayci R, Sasmaz T, Kaleagasi H, Kurt O, Karakelle A, et al. The sensitivity and specificity of the case definition criteria in diagnosis of headache: a school-based epidemiological study of 5562 children in Mersin. Cephalalgia. 2003 Mar; 23(2): 138-45.

45. Cevoli S, Sancisi E, Grimaldi D, Pierangeli G, Zanigni S, Nicodemo M, et al. Family history for chronic headache and drug overuse as a risk factor for headache chronification. Headache. 2009 Mar; 49(3): 412-18

46. Seshia SS, Abu-Arafeh I, Hershey AD. Tension-type headache in children: the Cinderella of headache disorders! Can J Neurol Sci. 2009; 36(6): 687-95

47. Montagna P, Cevoli S, Marzocchi N, Pierangeli G, Pini LA, Cortelli P, et al. The genetics of chronic headaches. Neurol Sci. 2003 May; 24 Suppl 2: S51-6.

48. da Silva Jr A, Costa EC, Gomes JB, Leite FM, Gomez RS, Vasconcelos LP, et al. Chronic headache and comorbidities: A two-phase, population-based, cross-sectional study. Headache. 2010 Feb 12. [Epub ahead of print]. PMID: 20163479.

49. American Psychiatric Association. Diagnostic and statistical manual of mental disorders, DSM-IV-TR. 4th ed. Text Revision ed. Washington, DC: American Psychiatric Association; 2000.

50. Fujita M, Fujiwara J, Maki T, Shibasaki K, Shigeta M, Nii J. Pediatric chronic daily headache associated with school phobia. Pediatr Int. 2009 Oct; 51(5): 621-25.

51. Galli F, Canzano L, Scalisi TG, Guidetti V. Psychiatric disorders and headache familial recurrence: a study on 200 children and their parents. J Headache Pain. 2009 Jun; 10(3): 187-97.

52. Goder R, Friege L, Fritzer G, Strenge H, Aldenhoff JB, Hinze-Selch D. Morning headaches in patients with sleep disorders: a systematic polysomnographic study. Sleep Med. 2003 Sep; 4(5): 385-91.

53. Paiva T, Farinha A, Martins A, Batista A, Guilleminault C. Chronic headaches and sleep disorders. Arch Intern Med. 1997 Aug 11$25 ; 157(15): 1701-5$

54. Rains JC, Poceta JS. Headache and sleep disorders: review and clinical implications for headache management. Headache. 2006 Oct; 46(9): 1344-63.

55. Vgontzas A, Cui L, Merikangas KR. Are sleep difficulties associated with migraine attributable to anxiety and depression? Headache. 2008 Nov-Dec; 48(10): 1451-9.

56. Bruni O, Fabrizi P, Ottaviano S, Cortesi F, Giannotti F, Guidetti V. Prevalence of sleep disorders in childhood and adolescence with headache: a case-control study. Cephalalgia. 1997 Jun; 17(4): 492-8.

57. Zarowski M, Mlodzikowska-Albrecht J, Steinborn B. The sleep habits and sleep disorders in children with headache. Adv Med Sci. 2007; 52 Suppl 1: 194-6.

58. Bruni O, Russo PM, Ferri R, Novelli L, Galli F, Guidetti V. Relationships between headache and sleep in a non-clinical population of children and adolescents. Sleep Med. $2008 \mathrm{Jul}$; 9(5): 542-8.

59. Vendrame M, Kaleyias J, Valencia I, Legido A, Kothare SV. Polysomnographic findings in children with headaches. Pediatr Neurol. 2008 Jul; 39(1): 6-11.

60. Gupta R, Bhatia MS, Dahiya D, Sharma S, Sapra R, et al. Impact of primary headaches on subjective sleep parameters among adolescents. Ann Indian Acad Neurol. 2008 Jul; 11(3): 164-9.

61. Isik U, Ersu RH, Ay P, Save D, Arman AR, Karakoc F, et al. Prevalence of headache and its association with sleep disorders in children. Pediatr Neurol. 2007 Mar; 36(3): 146-51.

62. Gilman DK, Palermo TM, Kabbouche MA, Hershey AD, Powers SW. Primary headache and sleep disturbances in adolescents. Headache. 2007 Sep; 47(8): 1189-94.

63. Scher AI, Stewart WF, Lipton RB. The comorbidity of headache with other pain syndromes. Headache. 2006 Oct; 46(9): 1416-23. 
64. Bigal ME, Lipton RB. Obesity and chronic daily headache. Curr Pain Headache Rep. 2008 Jan; 12(1): 56-61.

65. Hershey AD, Powers SW, Nelson TD, Kabbouche MA, Winner P, Yonker M, et al. American Headache Society pediatric adolescent section. Obesity in the pediatric headache population: a multicenter study. Headache. 2009 Feb; 49(2): 170-7.

66. Pinhas-Hamiel O, Frumin K, Gabis L, Mazor-Aronovich K, Modan-Moses D, Reichman B, et al. Headaches in overweight children and adolescents referred to a tertiary-care center in Israel. Obesity (Silver Spring). 2008 Mar; 16(3): 659-63.

67. Sillanpaa M, Piekkala P, Kero P. Prevalence of headache at preschool age in an unselected child population. Cephalalgia. 1991 Nov; 11(5): 239-42.

68. Karwautz A, Wober C, Lang T, Bock A, Wagner-Ennsgraber C, Vesely $\mathrm{C}$, et al. Psychosocial factors in children and adolescents with migraine and tension-type headache: a controlled study and review of the literature. Cephalalgia. 1999 Jan; 19(1): 32-43.

69. Juang KD, Wang SJ, Fuh JL, Lu SR, Chen YS. Association between adolescent chronic daily headache and childhood adversity: a community-based study. Cephalalgia. 2004 Jan; 24(1): 54-9.

70. Peterlin BL, Ward T, Lidicker J, Levin M. A retrospective, comparative study on the frequency of abuse in migraine and chronic daily headache. Headache. 2007 Mar; 47(3): 397-401.

71. Tietjen GE, Brandes JL, Peterlin BL, Eloff A, Dafer RM, Stein MR, et al. Childhood maltreatment and migraine (Part I). Prevalence and adult revictimization: a multicenter headache clinic survey. Headache. 2010 Jan; 50(1): 20-31.

72. Scher AI, Stewart WF, Lipton RB. Caffeine as a risk factor for chronic daily headache: A population-based study. Neurology. 2004 Dec 14; 63(11): 2022-7.

73. Srikiatkhachorn A. Chronic daily headache: a scientist's perspective. Headache. 2002 Jun; 42(6): 532-7.

74. Srikiatkhachorn A. Towards the better understanding about pathogenesis of chronic daily headache. J Med Assoc Thai. 2006 Sep; 89 Suppl 3: S234-43.

75. Nash JM, Thebarge RW. Understanding psychological stress, its biological processes, and impact on primary headache. Headache. 2006 Oct; 46(9): 1377-86.

76. Moskowitz MA. Defining a pathway to discovery from bench to bedside: the trigeminovascular system and sensitization. Headache. 2008 May; 48(5): 688-90.

77. Meng ID, Cao L. From migraine to chronic daily headache: the biological basis of headache transformation. Headache. 2007 Sep; 47(8): 1251-8.

78. Ji T, Mack KJ. Unilateral chronic daily headache in children. Headache. 2009 Jul; 49(7): 1062-5.

79. Bigal ME, Sheftell FD, Tepper SJ, Rapoport AM, Lipton RB. Migraine days decline with duration of illness in adolescents with transformed migraine. Cephalalgia. $2005 \mathrm{Jul}$; 25(7): 482-7.

80. Marmura MJ, Silberstein SD, Gupta M. Hemicrania continua: who responds to indomethacin? Cephalalgia. 2009 Mar; 29(3): 300-7.

81. Ramadan NM. Intracranial hypertension and migraine. Cephalalgia. 1993 Jun; 13(3): 210-11.

82. Mathew NT, Ravishankar K, Sanin LC. Coexistence of migraine and idiopathic intracranial hypertension without papilledema. Neurology. 1996 May; 46(5): 1226-30.

83. Wang SJ, Silberstein SD, Patterson S, Young WB. Idiopathic intracranial hypertension without papilledema: a case-control study in a headache center. Neurology. 1998 Jul; 51(1): 245-9.

84. Vieira DS, Masruha MR, Goncalves AL, Zukerman E, Senne Soares CA, Naffah-Mazzacoratti Mda G, et al. Idiopathic intracranial hypertension with and without papilloedema in a consecutive series of patients with chronic migraine. Cephalalgia. 2008 Jun; 28(6): 609-13.

85. Beri S, Gosalakkal JA, Hussain N, Balky AP, Parepalli S. Idiopathic intracranial hypertension without papilledema. Pediatr Neurol. 2010 Jan; 42(1): 56-8.

86. Riveira C, Pascual J. Is Chiari type I malformation a reason for chronic daily headache. Curr Pain Headache Rep. 2007 Feb; 11(1): 53-5.
87. Hershey AD, Powers SW, Vockell AL, LeCates S, Kabbouche MA, Maynard MK. PedMIDAS: development of a questionnaire to assess disability of migraines in children. Neurology. 2001 Dec 11; 57(11): 2034-9.

88. Kernick D, Campbell J. Measuring the impact of headache in children: a critical review of the literature. Cephalalgia. 2009 Jan; 29(1): 3-16

89. Lewis DW, Dorbad D. The utility of neuroimaging in the evaluation of children with migraine or chronic daily headache who have normal neurological examinations. Headache. 2000 Sep; 40(8): 629-32.

90. Abu-Arafeh I, Macleod S. Serious neurological disorders in children with chronic headache. Arch Dis Child. 2005 Sep; 90(9): 937-40

91. Torbey MT, Geocadin RG, Razumovsky AY, Rigamonti D, Williams MA. Utility of CSF pressure monitoring to identify idiopathic intracranial hypertension without papilledema in patients with chronic daily headache. Cephalalgia. 2004 Jun; 24(6): 495-502.

92. Eccleston C, Palermo TM, Williams AC, Lewandowski A, Morley S. Psychological therapies for the management of chronic and recurrent pain in children and adolescents. Cochrane Database Syst Rev. 2009 Apr 15; (2)(2): CD003968.

93. Sun Y, Gan TJ. Acupuncture for the management of chronic headache: a systematic review. Anesth Analg. 2008 Dec; 107(6): 2038-47.

94. Gottschling S, Meyer S, Gribova I, Distler L, Berrang J, Gortner L, et al. Laser acupuncture in children with headache: a doubleblind, randomized, bicenter, placebo-controlled trial. Pain. 2008 Jul 15; 137(2): 405-12.

95. Lewis DW, Winner P, Wasiewski W. The placebo responder rate in children and adolescents. Headache. 2005 Mar; 45(3): 232-9.

96. Schwartz TH, Karpitskiy VV, Sohn RS. Intravenous valproate sodium in the treatment of daily headache. Headache. 2002 Jun; 42(6): 519-22.

97. Charles JA, Jotkowitz S. Observations of the "carry-over effect" following successful termination of chronic migraine in the adolescent with short-term dihydroergotamine, dexamethasone and hydroxyzine: a pilot study. J Headache Pain. 2005 Feb; 6(1): $51-4$.

98. Borzy JC, Koch TK, Schimschock JR. Effectiveness of topiramate in the treatment of pediatric chronic daily headache. Pediatr Neurol. 2005 Nov; 33(5): 314-6.

99. Mack KJ, Gladstein J. Management of chronic daily headache in children and adolescents. Paediatr Drugs. 2008; 10(1): 23-9.

100. Prakash S, Husain M, Sureka DS, Shah NP, Shah ND. Is there need to search for alternatives to indomethacin for hemicrania continua? Case reports and a review. J Neurol Sci. 2009 Feb 15; 277(1-2): 187-90.

101. Marmura MJ, Passero FC Jr, Young WB. Mexiletine for refractory chronic daily headache: a report of nine cases. Headache. 2008 Nov-Dec; 48(10): 1506-10.

102. Chan VW, McCabe EJ, MacGregor DL. Botox treatment for migraine and chronic daily headache in adolescents. J Neurosci Nurs. 2009 Oct; 41(5): 235-43.

103. Guidetti V, Mittica P, Galli F. Evolution of chronic daily headache in children and adolescents: a 10-year follow-up study. Cephalalgia. 2009; 29((suppl 1)): 105.

104. Charles JA, Peterlin BL, Rapoport AM, Wang SJ, Fuh JL, Lu SR. Chronic daily headache in adolescents: an 8-year follow-up study. Neurology. 2010 Mar 2; 74(9): 780; author reply 780-1.

105. Solomon S, Lipton RB, Newman LC. Clinical features of chronic daily headache. Headache. 1992 Jul; 32(7): 325-9.

106. Srikiatkhachorn A, Phanthumchinda K. Prevalence and clinical features of chronic daily headache in a headache clinic. Headache. 1997 May; 37(5): 277-80.

107. Mack KJ, Hershey AD. Chronic daily headache in adolescence: a continuing problem. Neurology. 2009 Aug 11; 73(6): 412-3. 